\title{
Latent Infection of Powdery Mildew on Volunteer Wheat in Sichuan Province, China
}

\author{
Na Liu, ${ }^{1,2}$ Yu Lei, ${ }^{1,3}$ Min Zhang, ${ }^{1}$ Wenming Zheng, ${ }^{2}$ Yongchun Shi, ${ }^{2}$ Xiaobo Qi, ${ }^{1}$ Huabao Chen, ${ }^{1}$ You Zhou, ${ }^{1}$ and \\ Guoshu Gong1, $\dagger$
}

${ }^{1}$ College of Agronomy, Sichuan Agricultural University, Chengdu 611130, China; ${ }^{2}$ College of Life Sciences, Henan Agricultural

University, Zhengzhou, Henan, 450002, China; and ${ }^{3}$ College of Biological Engineering, Sichuan University of Science \& Engineering,

Zigong 643000, China

\begin{abstract}
Wheat powdery mildew, caused by the fungal pathogen Blumeria graminis f. sp. tritici, is one of the most destructive wheat diseases in China, especially in Sichuan Province. Successfully oversummered B. graminis f. sp. tritici can become a primary infection source for wheat seedlings in the fall. Determining the latent infection level of $B$. graminis f. sp. tritici in volunteer wheat and the oversummering areas of $B$. graminis f. sp. tritici is important for estimating potential B. graminis f. sp. tritici epidemics. In this study, we clarified the critical role of volunteer wheat in the B. graminis f. sp. tritici oversummering cycle and determined whether latent $B$. graminis f. sp. tritici infection was present in volunteer wheat by using real-time polymerase chain reaction (real-time PCR). The results indicated that volunteer wheat was mostly found in the northeast and middle regions of Sichuan, where lower temperatures and higher precipitation are common. A total of $13.2 \%$ of samples showed symptoms of

infection symptoms was found at an altitude of $536 \mathrm{~m}$ but volunteer wheat latently infected by $B$. graminis f. sp. tritici was identified at the lowest altitude of $323 \mathrm{~m}$. Crop shade (e.g., corn and lima bean) provided suitable conditions for the survival of volunteer wheat in the summer. In addition, volunteer wheat played a key role in the $B$. graminis f. sp. tritici oversummering cycle. Moreover, $B$. graminis f. sp. tritici could oversummer by infecting generations of volunteer wheat in the summer, thereby becoming the primary infection source for autumn-sown wheat. The results showed that the latent infection of wheat diseases could be rapidly quantified by real-time PCR. Here, the primary disease center of autumnsown wheat in Ya'an and Wenjiang were detected accurately based on this method. This study provides solid evidence for identifying the disease center, which offers guidance for wheat disease control and management.
\end{abstract} B. graminis f. sp. tritici (spores) in the field, and $36.8 \%$ of samples were found to carry the $B$. graminis f. sp. tritici pathogen, even though no symptoms were observed. Volunteer wheat with $B$. graminis f. sp. tritici

Keywords: Blumeria graminis f. sp. tritici, volunteer wheat, oversummering, real-time PCR

Wheat powdery mildew, caused by the biotrophic ascomycete fungus Blumeria graminis f. sp. tritici, is one of the most destructive wheat diseases worldwide (Bowen et al. 1991; Broscious et al. 1985; Costamilan 2005; Miller and Pollard 1976; Wang et al. 2015). The disease generally causes serious yield losses every year in almost all wheat-producing regions in China ( $\mathrm{Li}$ et al. 2016; Tang et al. 2017; Zhao et al. 2018), especially in Sichuan Province, where yield losses ascribable to powdery mildew have typically ranged from 5 to $8 \%$, sometimes reaching $50 \%$ or even $100 \%$ in some wheat fields (Liu et al. 2012). Successfully oversummered B. graminis f. sp. tritici on volunteer wheat can become a primary infection source for wheat seedlings in the fall (Cao et al. 2011; Duan et al. 1995; Gorlenko 1940; Jankovics et al. 2015; Li et al. 2013; Mzhavanadze 1974; Tu et al. 1999; Turner 1956). Whether B. graminis f. sp. tritici can oversummer depends on the local geographical environment and climatic conditions. Dry and rainless summers are beneficial to the survival of cleistothecia, while cool temperatures and suitable humidity allow B. graminis f. sp. tritici to continuously infect volunteer wheat in fields (Cao et al. 2011; Jankovics et al. 2015; Koltin and Kenneth 1970; Li et al. 1988; Padalino et al. 1970; Tursumbaev

${ }^{\dagger}$ Corresponding author: G. Gong; E-mail guoshugong@126.com

N. Liu and Y. Lei contributed equally to this study.

Funding: This work was financially supported by the National Key R\&D Program of China (2018YFD0200500), the Special Fund for Agroscientific Research in the Public Interest of China (201303016), and the Innovation Fund of Henan Agricultural University (KJCX2017A13).

The author(s) declare no conflict of interest.

Accepted for publication 25 January 2019.

() 2019 The American Phytopathological Society
1974; Yang and Liu 1994,). Cleistothecia and conidia can oversummer in Leningrad, Russia and in the south of Italy, becoming the initial inoculum for autumn-sown wheat (Padalino et al. 1970; Ts'ao 1960). In China, some studies have focused on investigating the environmental conditions required for oversummering (Lei et al. 1982; Li et al. 2013; Liu et al. 1990; Liu et al. 2012; Zhang and Li 1993). Liu et al. (1990) found that $B$. graminis f. sp. tritici could successfully oversummer only above an altitude of $530 \mathrm{~m}$ in the northwest of Henan. After years of observation in the Guanzhong area, Zhang and $\mathrm{Li}$ (1993) reported that it was difficult for B. graminis f. sp. tritici to oversummer in plains areas but that it could survive in cool and damp mountainous regions. Liu et al. (2012) demonstrated that, in Sichuan Province, $B$. graminis f. sp. tritici was able to oversummer at an altitude of $595 \mathrm{~m}$ and higher through field inoculation experiments using ascospores and conidia at different altitudes. Based on the quantitative relationship between temperature and wheat powdery mildew, Li et al. (2013) determined the zones of oversummering of wheat powdery mildew in China by using geographic information systems and geostatistics technology. The majority of those zones were located in mountainous regions of southwest China such as Yunnan, west of Guizhou and northwest of Sichuan (Li et al. 2013).

The latent period of powdery mildew in volunteer wheat is strongly influenced by environmental factors (e.g., temperature) and ranges from 4 to 28 days (Longrée 1939; Price 1970; Tao et al. 1976). The traditional method of determining latent $B$. graminis f. sp. tritici infection levels is time and labor intensive (Zheng et al. 2013). Real-time polymerase chain reaction (PCR) technologies have been widely used and have given rise to new research opportunities for detecting and studying phytopathogenic and antagonistic fungi (Gachon and Saindrenan 2004; Gayoso et al. 2007; Huang et al. 2017; Justesen et al. 2008; Nikitin et al. 2018; Schena et al. 2004; Winton et al. 2003; Zheng et al. 2013). Gachon and Saindrenan (2004) quantitatively monitored the growth of fungi from the first stage of infection via real-time PCR and demonstrated that this method could significantly discriminate between slightly different 
levels of resistance. Using artificially infected leaves, Zheng et al. (2013) established a linear relationship between the molecular disease index (MDX) and the observed disease index (DX) based on real-time PCR. Li et al. (2015) developed a duplex TaqMan realtime PCR method for quantifying Puccinia striiformis f. sp. tritici and $B$. graminis f. sp. tritici from air samples collected with spore traps. Estimation of the latent infection level is important for estimating inoculum potential and aids in timely decision making in disease management. However, the potential field application of this method needs to be confirmed with field experiments. Furthermore, few studies have addressed latent infections in volunteer wheat, which is an important inoculum source for autumn-sown wheat. Sichuan is an important location and has been reported to be a major area for powdery mildew oversummering. Even so, it is easy to ignore the influence of latent infection of volunteer wheat in disease management or research on the oversummering of wheat powdery mildew, which may influence regional disease epidemics in Sichuan Province and other parts of China through long-distance disease spreading.

In previous studies, we surveyed the oversummering of $B$. graminis f. sp. tritici on volunteer wheat in wheat production areas of Sichuan Province in 2008 and 2009 and systematically monitored volunteer wheat in the field (Liu et al. 2012) but the latent infection level of $B$. graminis f. sp. tritici in volunteer wheat was undefined. As mentioned above, the primary infection source for autumn-sown wheat is oversummered $B$. graminis f. sp. tritici on volunteer wheat. The objectives of this study were to determine the areas of $B$. graminis f. sp. tritici oversummering and to detect the latent infection level of $B$. graminis f. sp. tritici on volunteer wheat by real-time PCR, which provides a scientific foundation for future disease control through improved disease management.

\section{Materials and Methods}

Field investigation of natural survival conditions for volunteer wheat and its infection by $B$. graminis f. sp. tritici. The survival of volunteer wheat and its infection by $B$. graminis f. sp. tritici were investigated from mid-July to early September in the summers of 2011 and 2012 in the major wheat production areas of Sichuan Province. At least five fields in which wheat had been planted as a previous crop were investigated in each wheat-growing area. Natural volunteer wheat samples with no observable symptoms were collected for latent infection experiments. Three to five leaves of the wheat samples were collected into a tube and then placed in a chilled carrying container. The samples were transported back to the laboratory and stored at $-80^{\circ} \mathrm{C}$ for future use.

Systematic observation of volunteer wheat survival conditions and $\boldsymbol{B}$. graminis f. sp. tritici activity in different crops. To simulate the local planting pattern, two test fields (Ya'an and Wenjiang) located in different ecological conditions with continuous cropping of wheat with heavy $B$. graminis f. sp. tritici infection yearly were used to monitor the survival of volunteer wheat and B. graminis $\mathrm{f}$. sp. tritici infection on the wheat. The field in Ya'an at the farm of Sichuan Agricultural University, $29^{\circ} 98^{\prime} 042 \mathrm{~N}, 102^{\circ} 98^{\prime} 903 \mathrm{E}$ at an altitude of $595 \mathrm{~m}$, was monitored in summer 2011 and 2012, and the field experiment in Wenjiang was conducted at the experimental station of Huihe Valley, $30^{\circ} 43^{\prime} 098 \mathrm{~N}, 103^{\circ} 52^{\prime} 137 \mathrm{E}$ at an altitude of $536 \mathrm{~m}$, in summer 2012. The susceptible wheat cultivar Chuanyu 20 was grown as a previous crop throughout the entire wheat-cropping season in Ya' an and Wenjiang. The size of the field plot was approximately $200 \mathrm{~m}^{2}$ (10 by $20 \mathrm{~m}$ ) in each site. Corn and lima bean are sown after the wheat harvest in Sichuan Province. Therefore, after wheat harvesting (in the middle of May), the field was divided into two parts: one was planted with corn (Zea mays L.) and the other with lima bean (Vicia faba L.) to serve as cover shade for volunteer wheat. The fields were managed in a conventional manner with no herbicides. The survival conditions of the volunteer wheat and symptoms of $B$. graminis f. sp. tritici were recorded every week from the first group of volunteer wheat that emerged in late May until autumn sowing. Additionally, five volunteer wheat leaves with no symptoms were collected at each sampling point every 7 days for monitoring latent infection of $B$. graminis f. sp. tritici. The sample collection methods were the same as those described above. Disease notes and samples were taken in five locations of each plot to reduce experimental error.

Systematic observation of latent infection of autumnsown wheat. In autumn, the susceptible wheat variety Triticum aestivum L. 'Chuanyu 20' was sown under conventional methods in Ya' an and Wenjiang, where wheat was planted every year. An evaluation of powdery mildew on autumn-sown wheat and sampling of leaves with no symptoms occurred every 7 days from the two-leaf stage until B. graminis f. sp. tritici spores were first detected. Methods for taking disease notes and leaf samples were the same as previously mentioned.

Extraction of fungal and plant DNA. Genomic DNA of B. graminis f. sp. tritici (for standard curve) was extracted with a fungal DNA kit (Omega Bio-Tek, Norcross, GA, U.S.A.) following the manufacturer's protocol. The cetyltrimethylammonium bromide method was used to extract DNA from the sampled volunteer wheat leaf tissues (2-cm-long sections were removed) following the protocols, with minor modifications. The extracted DNA was diluted to $50 \mu \mathrm{l}$ of distilled water and diluted $60 \times$ and $500 \times$ for real-time PCR amplification of $B$. graminis f. sp. tritici DNA and wheat DNA, respectively.

Primers and real-time PCR assay. The specific pair of DNA primers Bgt-F (5'-AAGCTATGCGGAACTTCGTTT-3') and Bgt-R (5'-TAAGGAGTTTTGGCAAGTCCC-3'), designed by Zeng et al. (2010) based on an internal transcribed spacer sequence (Wyand and Brown 2003), was used to construct a standard curve for B. graminis f. sp. tritici, and the specific primers wheat-F1 (5'-CAACCACTCT CAACGGGAA-3') and wheat-R1 (5'-TCAAAGGTCATAATGC CAGC-3'), designed by Zheng et al. (2013), were used to construct a standard curve for wheat leaves.

Amplification was conducted in a $15-\mu 1$ volume containing $7.5 \mu \mathrm{l}$ of SYBR Premix Ex Taq, $0.3 \mu$ l of either forward or reverse primer $(5 \mu \mathrm{M}), 1.0 \mu \mathrm{l}$ of sample DNA template, and $5.9 \mu \mathrm{l}$ of doubledistilled $\mathrm{H}_{2} \mathrm{O}$. The following conditions were used for real-time PCR with the primer pair $B g t-\mathrm{F} / B g t-\mathrm{R}: 30 \mathrm{~s}$ at $95^{\circ} \mathrm{C}$, followed by 40 cycles of denaturation at $95^{\circ} \mathrm{C}$ for $5 \mathrm{~s}$, annealing at $59^{\circ} \mathrm{C}$ for 20 $\mathrm{s}$, and extension at $72^{\circ} \mathrm{C}$ for $20 \mathrm{~s}$. The following conditions were used to amplify the fragment of wheat genomic DNA using the primer pair wheat-F1/wheat-R1: an initial preheating for $30 \mathrm{~s}$ at $95^{\circ} \mathrm{C}$, followed by 40 cycles of denaturation at $95^{\circ} \mathrm{C}$ for $5 \mathrm{~s}$ with annealing and extension at $65^{\circ} \mathrm{C}$ for $30 \mathrm{~s}$.

Using the primer pair $B g t-\mathrm{F} / B g t-\mathrm{R}$ and $B$. graminis f. sp. tritici DNA, the peak of the melting curve was obtained under conditions of $95^{\circ} \mathrm{C}$ for $20 \mathrm{~s}$ and $59^{\circ} \mathrm{C}$ for $20 \mathrm{~s}$, and fluorescence was read every $10 \mathrm{~s}$ per $0.5^{\circ} \mathrm{C}$ increase from 55 to $95^{\circ} \mathrm{C}$. Using the primer pair wheat$\mathrm{F} 1 /$ wheat-R1 and wheat DNA, the melting curve peak was obtained under the conditions of $95^{\circ} \mathrm{C}$ for $20 \mathrm{~s}$ and $65^{\circ} \mathrm{C}$ for $10 \mathrm{~s}$, and fluorescence was read every $10 \mathrm{~s}$ per $0.5^{\circ} \mathrm{C}$ increase from 55 to $95^{\circ} \mathrm{C}$.

Standard curves and statistical analyses. To construct standard curves for B. graminis f. sp. tritici (using standard isolate Bgt-56) and uninfected wheat leaves (using the wheat cultivar Chinese Spring), B. graminis f. sp. tritici DNA or wheat leaf DNA was diluted to $1 \mathrm{ng}, 100 \mathrm{pg}, 10 \mathrm{pg}, 100 \mathrm{fg}, 10 \mathrm{fg}$, and $1 \mathrm{fg}$, and each concentration was repeated three times. It was important to determine whether the genomic DNA of wheat would affect the real-time PCR of B. graminis f. sp. tritici. DNA with known concentrations, as described above, were mixed with $10 \mathrm{ng}$ of wheat DNA isolated from uninfected leaves, and a standard curve of real-time PCR using Bgt-F/Bgt-R was constructed. The mixed wheat DNA standard curve of $B$. graminis f. sp. tritici was compared with the standard curve of pure $B$. graminis f. sp. tritici with Statistical Product and Service Solutions (SPSS) v. 23 software (SAS Institute, Cary, NC, U.S.A.).

The quantities of $B$. graminis $\mathrm{f}$. sp. tritici and wheat leaf DNA were estimated using their standard curves and the MDX, which is the ratio of DNA quantity of $B$. graminis $\mathrm{f}$. sp. tritici and wheat.

\section{Results}

Field investigation of natural volunteer wheat and its infection by $\boldsymbol{B}$. graminis f. sp. tritici. Volunteer wheat was surveyed in the wheat-growing regions of Sichuang Province, including Guangyuan, Bazhong, Mianyang, Dazhou, Deyang, Nanchong, Chengdu, 
Suining, Guang'an, Ziyang, Meishan, Ya'an, Leshan, Neijiang, Zigong, Luzhou, and Yibin, in summer 2010, 2011, and 2012. Infected volunteer wheat was found in Guangyuan, Bazhong, and Ya'an, and volunteer wheat with no symptoms was observed in Mianyang, Deyang, Nanchong, Chengdu (Shuangliu), Suining, and Meishan. No volunteer wheat was observed in Dazhou, Guang'an, Ziyang, Leshan, Neijiang, Zigong, Luzhou, and Yibin in summer 2010. Survey results from 2011 and 2012 are shown in Figure 1. Volunteer wheat was heavily infected in the regions of Guangyuan, Deyang, Chengdu, and Ya'an during these 2 years. Symptomatic and asymptomatic volunteer wheat was observed in Bazhong in summer 2011 but only volunteer wheat with no symptoms was found in this region in summer 2012. There was abundant volunteer wheat in Mianyang, Dazhou, Nanchong, Suining, Guang'an, Ziyang, Meishan, and Leshan during the 2 years, whereas no volunteer wheat was found in Neijiang, Zigong, Luzhou, and Yibin in the 2 years.

Systematic observation of volunteer wheat survival conditions and $B$. graminis f. sp. tritici infection in Ya'an and Wenjiang. Survival conditions of volunteer wheat and $B$. graminis f. sp. tritici symptom had been systematically evaluated in the field of Ya'an for 3 years (2010 to 2012). The results for the 3 years showed that copious amounts of volunteer wheat could be found in the field 1 week after wheat harvest. Most of the wheat withered due to the hot and dry environment before or during the hottest days in summer. However, a few volunteer wheat plants survived and even set seed. Volunteer wheat in different stages could be observed during the autumn sowing season. The surviving volunteer wheat provided good hosts for the $B$. graminis f. sp. tritici infection and spread.

The oversummering cycle of $B$. graminis $\mathrm{f}$. sp. tritici on volunteer wheat in this test field provided a green bridge for powdery mildew oversummering. A schematic diagram of the $B$. graminis $\mathrm{f}$. sp. tritici cycle in Ya'an in Sichuan is shown in Figure 2. The fluctuation of the B. graminis f. sp. tritici infection status of volunteer wheat was determined. In early June (nearly 7 to 10 days after the wheat harvest), a large number of volunteer wheat plants emerged, and some showed symptoms of B. graminis f. sp. tritici (spores), with a disease incidence (DI) of $1 \%$. As time progressed, the number of infected plants and the severity of infection

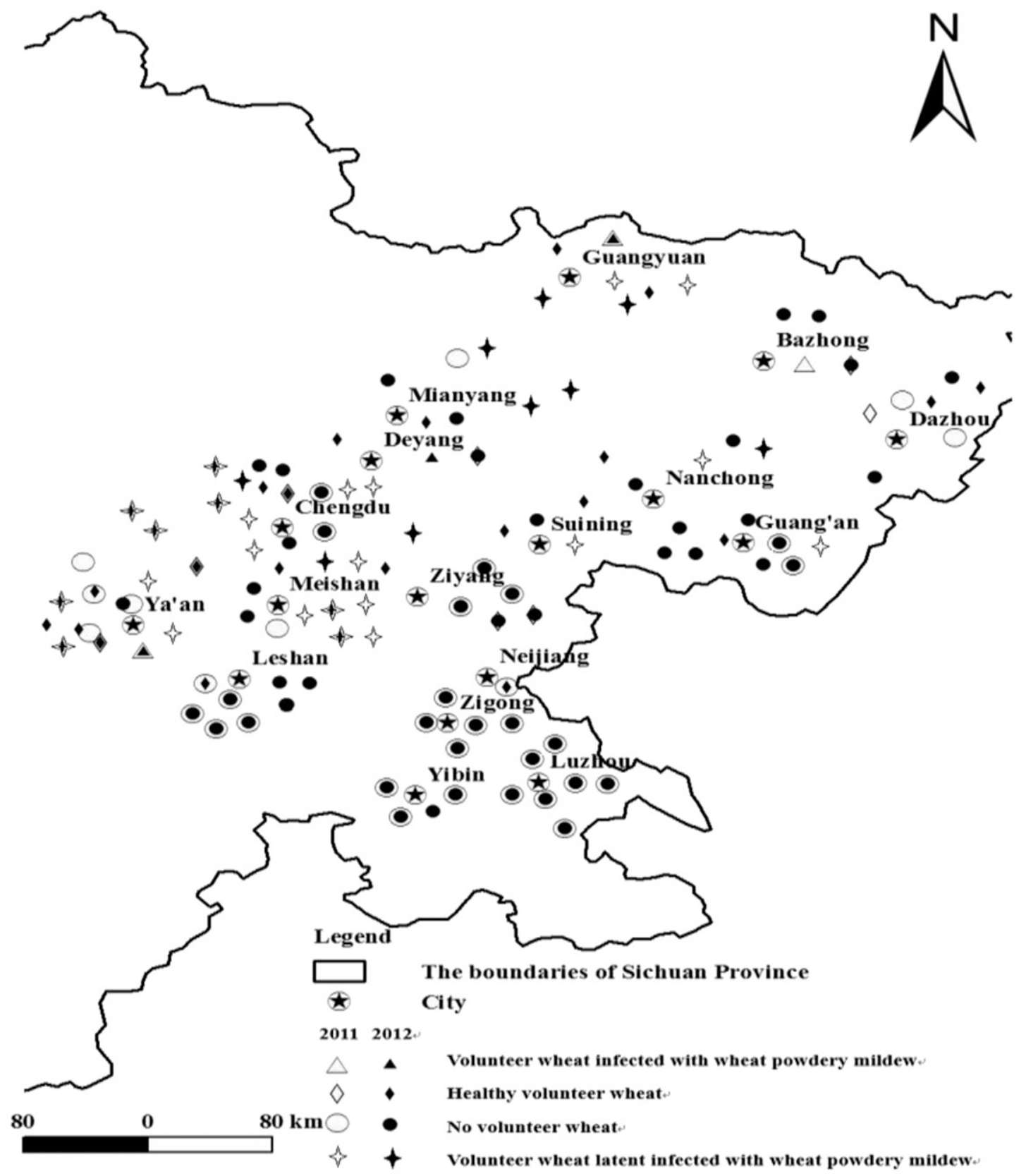

Fig. 1. Investigation of volunteer wheat and latent infection of Blumeria graminis f. sp. tritici in Sichuan Province (2011 to 2012). 
increased. The peak occurred between late July and early August, with a DI of approximately 50 to $60 \%$. In the middle of August, most volunteer wheat exposed to direct sunlight died due to high temperatures. Some volunteer wheat survived under the shade of corn or lima bean crops. The DI of powdery mildew in this period rapidly declined due to the low humidity and high temperature. During this time, the DI declined from approximately 50 to $60 \%$ to approximately 5 to $10 \%$. In early September, few volunteer wheat plants surviving under the shade of corn or lima bean crops could set seed. In the common field, some volunteer wheat showed symptoms of B. graminis f. sp. tritici until November. Some of the seed grown in different stages were observed in late October due to reasons such as weather, after-cropping, or being buried to different depths. Therefore, volunteer wheat crops were found at different stages (Fig. 3) from the seedling to booting stage, and some were heavily infected by $B$. graminis f. sp. tritici.

The same experiment was carried out in Wenjiang in 2012. The findings were similar to the results obtained in Ya'an. Due to the different geographic environments, the average temperature of Wenjiang is higher than that of Ya'an, whereas the humidity in Wenjiang is lower than that in Ya'an. The DI and disease severity in volunteer wheat in Wenjiang were relatively lower than in Ya'an. DI reached a peak value of $40 \%$ in the Wenjiang experimental field.

There was an obvious difference between the corn and lima bean treatments. In particular, in August, most of the volunteer wheat exposed to direct sunlight died. At that time, corn was at the silking stage, while lima bean was at the podding stage. Although both of these crops can provide shade to volunteer wheat, corn is taller and its leaves are larger than those of lima bean; thus, corn can provide more shade. The investigation results showed that the survival, infection, and infection severity of volunteer wheat in the corn field were higher than those in the lima bean field.

DNA standard curves. Both standards for $B$. graminis f. sp. tritici and wheat DNA were used in each run with the unknown samples. The primer pair $B g t-\mathrm{F} / B g t-\mathrm{R}$ was specific to $B$. graminis $\mathrm{f}$. $\mathrm{sp}$. tritici (Zeng et al. 2010). A standard curve was constructed by plotting known concentrations of $B$. graminis $\mathrm{f}$. sp. tritici DNA against the cycle threshold $(\mathrm{Ct})$ value obtained from real-time PCR. The equation was $y=-0.3057 x+3.8398$, where $r^{2}=0.999, x$ represents the $\mathrm{Ct}$ value, and $y$ is the $\log _{10} B$. graminis f. sp. tritici DNA quantity in micrograms. Likewise, the primer pair wheatF1/wheat-R1 was specific to wheat. The corresponding equation was $y=-0.2675 x+3.9246$, where $r^{2}=0.985, x$ represents the Ct value, and $y$ is the $\log _{10}$ B. graminis f. sp. tritici DNA quantity in micrograms. For the standard curve constructed with the mixed DNA of B. graminis f. sp. tritici and wheat, the equation was $y=$ $-0.3204 x+4.4054$, where $r^{2}=0.976, x$ represents the $\mathrm{Ct}$ value, and $y$ is $\log _{10} B$. graminis f. sp. tritici DNA quantity in micrograms. The covariance analysis results between the standard curve constructed with pure $B$. graminis f. sp. tritici DNA and that constructed with the mixed DNA of $B$. graminis f. sp. tritici and wheat (slope: $F=1.575, P=0.217>0.05$; intercept: $F=3.765$, $P=0.06>0.05$, by SPSS software) showed that the addition of host DNA had no effect on pathogen DNA quantification. Therefore, the amount of $B$. graminis f. sp. tritici DNA in latent leaves can be calculated with the above equation.

Quantification of B. graminis f. sp. tritici DNA in volunteer wheat from natural and systematic field observations. In total, 76 volunteer wheat samples were collected from Sichuan Province in 2011 and 2012. B. graminis f. sp. tritici DNA and wheat DNA

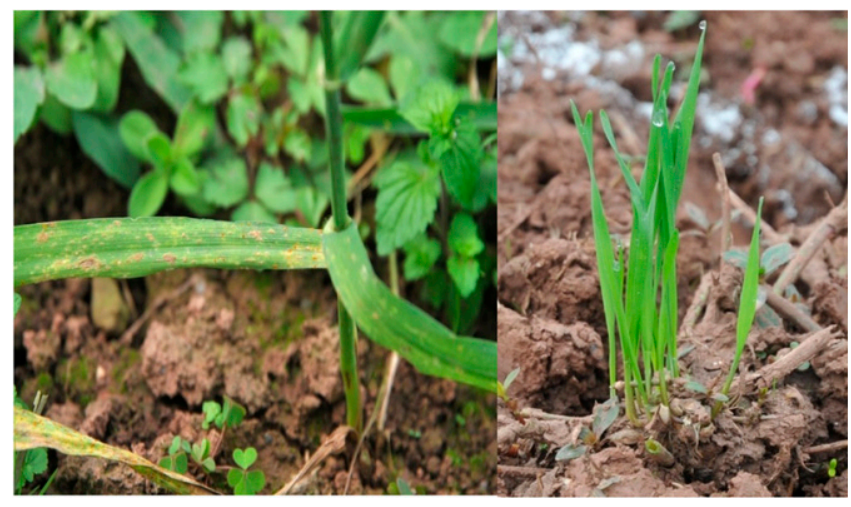

Fig. 3. Volunteer wheat in the field.

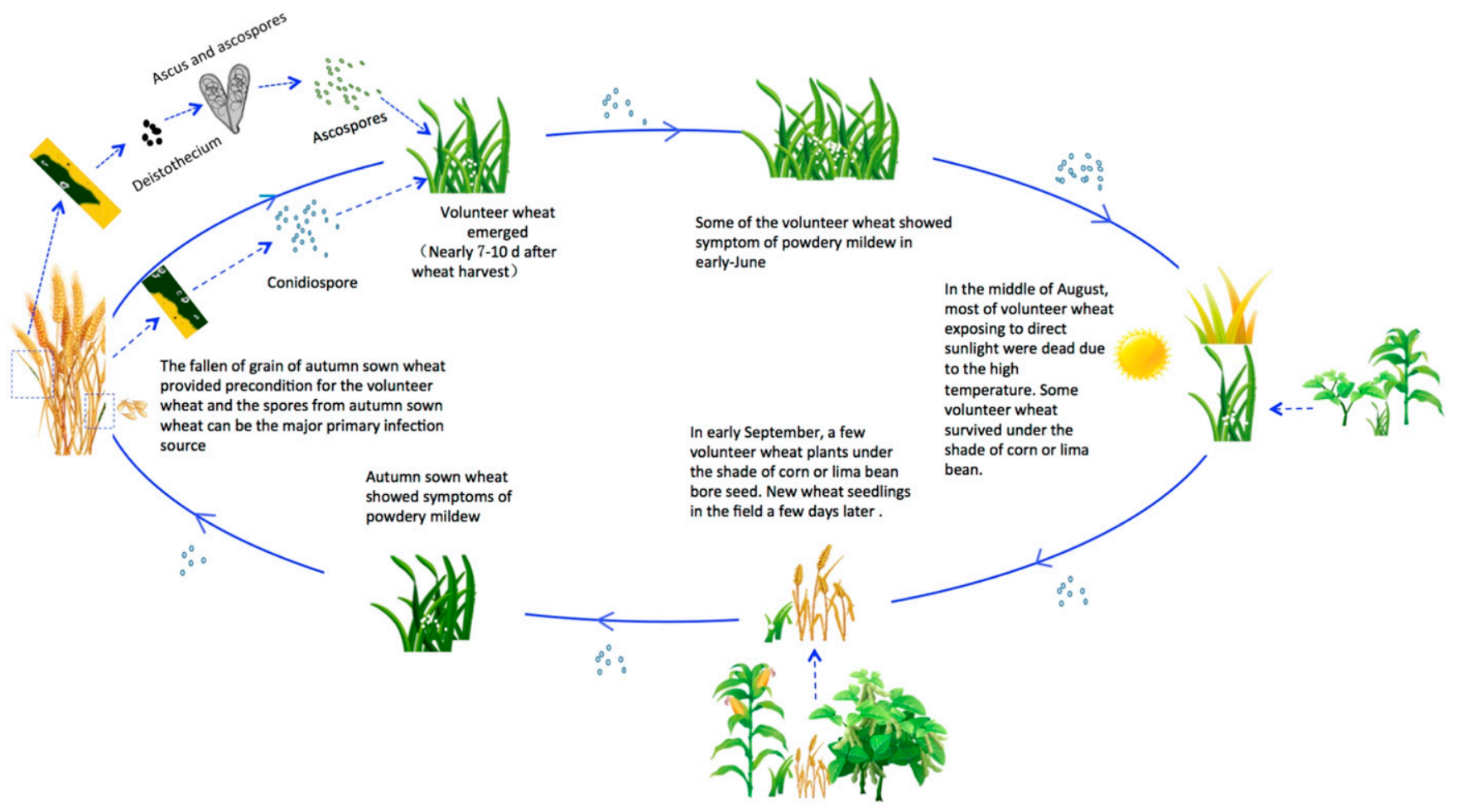

Fig. 2. Oversummering cycle of Blumeria graminis $\mathrm{f}$. sp. tritici on volunteer wheat. 
in the samples were quantified using real-time PCR with SYBR Green. Information for the samples and their MDX values is shown in Table 1 (2011) and Table 2 (2012).

In 2011, 41 volunteer wheat samples were tested. Among the samples, 6 of 41 samples (14.6\%) showed symptoms of $B$. graminis f. sp. tritici (spores) in the field. Three of these samples were collected from Ya'an, and the other three were from Guangyuang, Bazhong, and Deyang. The altitudes of the four sampling positions were above $543 \mathrm{~m}$. Through real-time PCR detection, 16 of 41 samples (39.0\%) were found to carry the B. graminis f. sp. tritici pathogen, even though they exhibited no obvious symptoms. The detection results showed that the percentage of wheat leaves carrying B. graminis f. sp. tritici was much higher than what was observed. The MDX value of these samples was between 0.0001 and 66.3450, and the lowest altitude of latent infection was 323 m (Jingtai, Nanchong).

In 2012, in total, 4 of 35 samples (11.4\%) showed symptoms of spores. The altitude of the four sampling plots was above $536 \mathrm{~m}$. The latent infection rate reached $40.0 \%$, although real-time PCR detection was more than triple that of the observations. The MDX value was between 0.0014 and 2.9105. The lowest altitude of latent infection was $516 \mathrm{~m}$ (Qinglian, Jiangyou).
Two test fields for fixed-point system observation of latent infection were set in Wenjiang and Ya'an. Sampling times and the MDX values of the fields are shown in Table 3 . In all, 15 of 20 volunteer wheat samples $(75.0 \%)$ were latently infected by B. graminis f. sp. tritici in Wenjiang, and 15 of 18 samples $(83.3 \%$ ) also carried B. graminis f. sp. tritici in Ya'an. The highest MDX values in Wenjiang and Ya'an were 1.1286 and 21.0173, respectively. It was obvious that most of the volunteer wheat was latently infected by $B$. graminis $\mathrm{f}$. sp. tritici from early June to November.

Systematic observation of latently infected autumn-sown wheat. Wheat was sown during late October and early September 2012. Five plots of autumn-sown wheat leaves were sampled in the fixed-point observation fields in Wenjiang and Ya'an. Leaves sampled from two of the five plots in Wenjiang field on 26 November were latently infected by B. graminis f. sp. tritici according to the real-time PCR results (Table 4). Leaves from one of the sampled plots showed symptoms of $B$. graminis $\mathrm{f}$. sp. tritici in early December 2012. The disease rate reached 64\%, and the disease index reached 17.36 on 18 March 2013.

Two plots among the five sampled on 16 November from the Ya'an field were found to be latently infected by B. graminis f. sp. tritici (the MDX of one was 0.0005 and that of the other was 0.0009) according to real-time PCR results. Leaves from one of the

Table 1. Investigation of volunteer wheat and latent infection of Blumeria graminis $\mathrm{f}$. sp. tritici based on real-time polymerase chain reaction detection (2011)

\begin{tabular}{|c|c|c|c|c|c|c|}
\hline Code & Place & Latitude & Longitude & Altitude (m) & MDX $^{\mathbf{a}}$ & Note \\
\hline 1 & Ma'an village, Meishan & $29^{\circ} 55.463$ & $104^{\circ} 18.033$ & 445 & 0.0160 & $\ldots$ \\
\hline 2 & Nanhe village, Meishan & $29^{\circ} 56.246$ & $104^{\circ} 17.042$ & 428 & - & $\ldots$ \\
\hline 3 & Manjing town, Meishan & $29^{\circ} 55.276$ & $104^{\circ} 08.563$ & 439 & 0.3723 & $\ldots$ \\
\hline 4 & Xinmin town, Chengdu 1\# & $30^{\circ} 89.821$ & $104^{\circ} 09.844$ & 513 & 0.2130 & $\ldots$ \\
\hline 5 & Xinmin town, Chengdu 2\# & $30^{\circ} 89.685$ & $104^{\circ} 09.734$ & 522 & - & $\ldots$ \\
\hline 6 & Banzuyuan town, Chengdu 1\# & $30^{\circ} 81.877$ & $104^{\circ} 06.805$ & 508 & 0.4429 & $\ldots$ \\
\hline 7 & Tianjiasi village, Chengdu 1\# & $30^{\circ} 46.701$ & $104^{\circ} 05.441$ & 451 & - & $\ldots$ \\
\hline 8 & Tianjiasi village, Chengdu 2\# & $30^{\circ} 46.613$ & $104^{\circ} 05.277$ & 457 & - & $\ldots$ \\
\hline 9 & Qingren town, Ya'an & $30^{\circ} 12.295$ & $102^{\circ} 56.204$ & 736 & 0.0001 & $\ldots$ \\
\hline 10 & Luyang town, Ya'an & $30^{\circ} 09.133$ & $102^{\circ} 55.341$ & 674 & - & $\ldots$ \\
\hline 11 & Baishi village, Ya'an & $30^{\circ} 04.525$ & $102^{\circ} 46.268$ & 844 & 0.1963 & $\ldots$ \\
\hline 12 & Shili village, Ya'an & $30^{\circ} 05.159$ & $102^{\circ} 47.034$ & 852 & - & $\ldots$ \\
\hline 13 & Baoxing country, Ya'an & $30^{\circ} 22.052$ & $102^{\circ} 48.523$ & 1,629 & 0.0024 & Symptoms \\
\hline 14 & Farm of SAU, Ya'an 1\# & $29^{\circ} 98^{\prime} 042$ & $102^{\circ} 98^{\prime} 903$ & 595 & 0.2198 & Symptoms \\
\hline 15 & Farm of SAU, Ya'an 2\# & $29^{\circ} 98^{\prime} 033$ & $102^{\circ} 97^{\prime} 973$ & 597 & 0.0001 & Symptoms \\
\hline 16 & Shuangjiang town, Qionglai 1\# & $30^{\circ} 23^{\prime} 412$ & $103^{\circ} 33^{\prime} 192$ & 505 & 66.3450 & $\ldots$ \\
\hline 17 & Shuangjiang town, Qionglai 2\# & $30^{\circ} 16^{\prime} 303$ & $103^{\circ} 26^{\prime} 367$ & 506 & 45.2353 & $\ldots$ \\
\hline 18 & Fenghuang village, Qionglai 1\# & $30^{\circ} 24^{\prime} 097$ & $103^{\circ} 32^{\prime} 531$ & 501 & - & $\ldots$ \\
\hline 19 & Fenghuang village, Qionglai 2\# & $30^{\circ} 24^{\prime} 882$ & $103^{\circ} 32^{\prime} 889$ & 503 & - & $\ldots$ \\
\hline 20 & Yongshou town, Meishan 1\# & $29^{\circ} 58^{\prime} 594$ & $103^{\circ} 50^{\prime} 177$ & 452 & 0.3648 & $\ldots$ \\
\hline 21 & Yongshou town, Meishan 2\# & $29^{\circ} 58^{\prime} 346$ & $103^{\circ} 50^{\prime} 752$ & 447 & - & $\ldots$ \\
\hline 22 & Xiasi town, Guangyuan 1\# & $32^{\circ} 16^{\prime} 507$ & $105^{\circ} 30^{\prime} 471$ & 543 & 0.0129 & Symptoms \\
\hline 23 & Xiasi town, Guangyuan 2\# & $32^{\circ} 16^{\prime} 775$ & $105^{\circ} 30^{\prime} 355$ & 551 & - & $\ldots$ \\
\hline 24 & Donghe town, Guangyuan 1\# & $32^{\circ} 13^{\prime} 461$ & $106^{\circ} 19^{\prime} 037$ & 650 & - & $\ldots$ \\
\hline 25 & Donghe town, Guangyuan 2\# & $32^{\circ} 13^{\prime} 396$ & $106^{\circ} 19^{\prime} 019$ & 675 & - & $\ldots$ \\
\hline 26 & Jintai town, Nanchong & $30^{\circ} 55.356$ & $106^{\circ} 06.511$ & 323 & 0.1023 & $\ldots$ \\
\hline 27 & Xinsheng town, Mianyang 1\# & $30^{\circ} 94.221$ & $105^{\circ} 06.697$ & 396 & - & $\ldots$ \\
\hline 28 & Xinsheng town, Mianyang 2\# & $30^{\circ} 94.084$ & $105^{\circ} 06.590$ & 526 & - & $\ldots$ \\
\hline 29 & Zhongxin village, Dazhou & $31^{\circ} 34.216$ & $107^{\circ} 52.624$ & 350 & - & $\ldots$ \\
\hline 30 & Zhuxian village, Dazhou & $31^{\circ} 37.054$ & $107^{\circ} 52.224$ & 362 & - & $\ldots$ \\
\hline 31 & Liuqiao village, Guang'an & $30^{\circ} 31.042$ & $106^{\circ} 48.445$ & 345 & - & $\cdots$ \\
\hline 32 & Zhaizi village, Guang'an & $30^{\circ} 29.311$ & $106^{\circ} 41.195$ & 291 & - & $\ldots$ \\
\hline 33 & Zhenhe village, Guang'an & $30^{\circ} 26.571$ & $106^{\circ} 36.299$ & 381 & - & $\ldots$ \\
\hline 34 & Gongqiao village, Deyang & $31^{\circ} 14.664$ & $104^{\circ} 39.422$ & 499 & - & $\ldots$ \\
\hline 35 & Longfeng village, Deyang & $31^{\circ} 09.276$ & $104^{\circ} 27.002$ & 553 & 0.0023 & Symptoms \\
\hline 36 & Xintai village, Suining & $30^{\circ} 55.708$ & $105^{\circ} 48.162$ & 296 & - & $\ldots$ \\
\hline 37 & Qianfo town, Leshan 1\# & $29^{\circ} 58.898$ & $104^{\circ} 05.511$ & 388 & - & $\ldots$ \\
\hline 38 & Qianfo town, Leshan 2\# & $29^{\circ} 58.679$ & $104^{\circ} 05.509$ & 385 & - & $\ldots$ \\
\hline 39 & Yingjie town, Ziyang & $30^{\circ} 06.708$ & $104^{\circ} 58.559$ & 403 & - & $\ldots$ \\
\hline 40 & Mazhan town, Ziyang & $30^{\circ} 50.918$ & $104^{\circ} 50.965$ & 392 & - & $\ldots$ \\
\hline 41 & Hongshantang town, Bazhong & $31^{\circ} 97.808$ & $107^{\circ} 41.921$ & 870 & 0.1223 & Symptoms \\
\hline
\end{tabular}

${ }^{\mathrm{a}}$ Molecular-detected disease index $(\mathrm{MDX})=\mathrm{DNA}(\mu \mathrm{g})$ of B. graminis f. sp. tritici/DNA (mg) of wheat; - indicates that no B. graminis f. sp. tritici was detected. 
sampled plots were found to exhibit spores of $B$. graminis f. sp. tritici in late November 2012 (Table 4). In mid-March 2013, the diseased leaf rate was $69 \%$ and the disease index was 21.7600 .

\section{Discussion}

The real-time PCR assay was shown to be a useful tool for quantifying latent infection levels and a key basis for determining the disease center accurately and in a timely fashion. We surveyed the infection of $B$. graminis f. sp. tritici and the survival of volunteer wheat in the main wheat-growing area in Sichuan Province after the hottest days in the summer for 3 years. The investigation results were consistent over the 3 years. Large numbers of volunteer wheat plants with no symptoms of $B$. graminis $\mathrm{f}$. sp. tritici were observed in many fields, and most of these fields were located in the northeast and middle of Sichuan; no volunteer wheat was found in the south of Sichuan (e.g., Luzhou and Yibin). The volunteer wheat producing spores of B. graminis f. sp. tritici occurred in relatively cooler locations in Sichuan Province such as Ya' an and Guangyuan during the summer. The distribution and infection of $B$. graminis $\mathrm{f}$. sp. tritici on volunteer wheat was always present at higher altitudes or latitudes as well as in regions with abundant precipitation, which suggested that the infections were closely related to temperature and humidity. Cao et al. (2011) investigated the oversummering of B. graminis f. sp. tritici under different ecological conditions and at different altitudes in Tianshui of Gansu Province and found that it could oversummer easily by means of conidia on volunteer wheat seedlings above an altitude of $1,270 \mathrm{~m}$, especially in plains and shady mountains. From 1991 to 2001, the lower limit of the oversummering altitude was 500 to $850 \mathrm{~m}$ in the Guanzhong area of Shanxi Province (Duan et al. 2002). In Sichuan Province, B. graminis f. sp. tritici could oversummer through conidia at an altitude of $595 \mathrm{~m}$ (latitude: $29^{\circ}$ $98^{\prime} 031 \mathrm{~N}$ ) and above (Liu et al. 2012). In the investigation of natural volunteer wheat conducted this study, a small portion of the collected volunteer wheat samples ( 14 of $76 ; 18.4 \%$ ) were located at an altitude above $595 \mathrm{~m}$. In all, 6 volunteer samples were healthy, and the remainder had symptoms of $B$. graminis f. sp. tritici (6 of 14) or were shown to harbor the pathogen by real-time PCR ( 2 of 14$)$. The presence of healthy volunteer wheat samples may be due to a lack of inoculum sources or unsuitable infection conditions (Longrée 1939; Price 1970; Tao et al. 1976). Another obvious characteristic of the investigation results was that the distribution and infection of volunteer wheat (including latent infection) was affected by cultivation practices. In the south of Sichuan, after wheat harvesting, growers tend to plant vegetables, including cabbage (Brassica oleracea L. var. capitata L.), pepper (Capsicum annuum L.), and others. Vegetables usually require relatively intensive cultivation. In this case, it is difficult for volunteer wheat to survive. In the north of Sichuan, farmers are inclined to grow food crops such as corn and lima bean after wheat harvesting. Generally, these crops are under extensive management; thus, they may provide more possibilities for the survival and infection of volunteer wheat. According to our natural survey data, volunteer wheat latently infected by Blumeria graminis f. sp. tritici was found at the lowest altitude of $323 \mathrm{~m}$, while volunteer wheat with $B$. graminis f. sp. tritici infection symptoms (spores appeared) was found at the lowest altitude of $536 \mathrm{~m}$. Thus, $B$. graminis $\mathrm{f}$. sp. tritici may oversummer on volunteer wheat at an altitude of $536 \mathrm{~m}$ under a suitable environment but this finding requires further study for confirmation.

Real-time PCR was used to identify $B$. graminis f. sp. tritici in spring or winter wheat or air (Li et al. 2015; Zheng et al. 2013). However, few studies conducted thus far have focused on the latent

Table 2. Investigation of volunteer wheat and latent infection of Blumeria graminis f. sp. tritici based on real-time polymerase chain reaction detection (2012)

\begin{tabular}{|c|c|c|c|c|c|c|}
\hline Code & Place & Latitude & Longitude & Altitude(m) & MDX $^{\mathbf{a}}$ & Notes \\
\hline 1 & Qinglong town, Meishan & $30^{\circ} 19.120$ & $103^{\circ} 52.031$ & 455 & 0.0115 & $\ldots$ \\
\hline 2 & Xiejia town, Meishan & $30^{\circ} 13.429$ & $103^{\circ} 46.657$ & 442 & - & $\ldots$ \\
\hline 3 & Xiasi town, Guangyuan & $32^{\circ} 27.313$ & $105^{\circ} 51.691$ & 543 & 0.0114 & Symptoms \\
\hline 4 & Panlong town, Guangyuan & $32^{\circ} 37.907$ & $105^{\circ} 62.607$ & 537 & 0.0351 & .. \\
\hline 5 & Donghe town, Guangyuan & $32^{\circ} 13^{\prime} 461$ & $106^{\circ} 19^{\prime} 037$ & 650 & - & $\ldots$ \\
\hline 6 & Huachao village, Jianyang & $30^{\circ} 16^{\prime} 137$ & $104^{\circ} 30^{\prime} 544$ & 483 & 2.9105 & $\ldots$ \\
\hline 7 & Wheat breeding base, Qionglai 1\# & $30^{\circ} 24^{\prime} 336$ & $103^{\circ} 32^{\prime} 735$ & 503 & 2.1021 & $\ldots$ \\
\hline 8 & Wheat breeding base, Qionglai 2\# & $30^{\circ} 24^{\prime} 304$ & $103^{\circ} 32^{\prime} 224$ & 504 & 0.0600 & $\ldots$ \\
\hline 9 & Shuangjiang town, Qionglai & $30^{\circ} 23^{\prime} 412$ & $103^{\circ} 33^{\prime} 192$ & 501 & - & $\ldots$ \\
\hline 10 & Qinlian town, Mianyang & $31^{\circ} 67.789$ & $104^{\circ} 68.278$ & 516 & 0.0265 & $\ldots$ \\
\hline 11 & Songya town, Mianyang & $31^{\circ} 37.999$ & $104^{\circ} 85.648$ & 494 & - & $\ldots$ \\
\hline 12 & Wenchang town, Mianyang & $31^{\circ} 65.272$ & $105^{\circ} 15.730$ & 502 & 0.1402 & $\ldots$ \\
\hline 13 & Farm of SAU, Ya'an 1\# & $29^{\circ} 98^{\prime} 023$ & $102^{\circ} 98^{\prime} 892$ & 597 & 0.0159 & Symptoms \\
\hline 14 & Farm of SAU, Ya' an 2\# & $29^{\circ} 98^{\prime} 031$ & $102^{\circ} 97^{\prime} 972$ & 595 & 0.0014 & Symptoms \\
\hline 15 & Farm of SAU, Ya'an 3\# & $29^{\circ} 98^{\prime} 042$ & $102^{\circ} 97^{\prime} 977$ & 597 & - & $\ldots$ \\
\hline 16 & Huayang town, Chengdu & $30^{\circ} 46.566$ & $104^{\circ} 05.392$ & 453 & - & $\ldots$ \\
\hline 17 & Huihe village, Chengdu & $30^{\circ} 43.098$ & $103^{\circ} 52.137$ & 536 & 0.1386 & Symptoms \\
\hline 18 & Yongning town, Chengdu & $30^{\circ} 42.289$ & $103^{\circ} 51.529$ & 537 & 1.1286 & $\ldots$ \\
\hline 19 & Huayuan town, Chengdu & $30^{\circ} 30.436$ & $103^{\circ} 52.493$ & 512 & 0.4826 & $\ldots$ \\
\hline 20 & Qunlie village, Chengdu 1\# & $30^{\circ} 37.507$ & $104^{\circ} 00.145$ & 497 & - & $\ldots$ \\
\hline 21 & Qunlie village, Chengdu 2\# & $30^{\circ} 37.455$ & $104^{\circ} 00.179$ & 495 & - & $\ldots$ \\
\hline 22 & Banzuyuan town, Chengdu & $30^{\circ} 81.813$ & $104^{\circ} 06.654$ & 511 & - & $\ldots$ \\
\hline 23 & Guihu village, Chengdu & $30^{\circ} 49.342$ & $104^{\circ} 09.353$ & 532 & 0.4429 & $\ldots$ \\
\hline 24 & Hu'an town, Guang'an 1\# & $30^{\circ} 50.357$ & $106^{\circ} 70.288$ & 275 & - & $\ldots$ \\
\hline 25 & Hu'an town, Guang'an 2\# & $30^{\circ} 50.539$ & $106^{\circ} 69.767$ & 330 & - & $\ldots$ \\
\hline 26 & Hanshi village, Guang'an & $30^{\circ} 49.344$ & $106^{\circ} 71.872$ & 321 & - & $\ldots$ \\
\hline 27 & Senjiagou village, Suining & $30^{\circ} 53.045$ & $105^{\circ} 62.136$ & 297 & - & $\ldots$ \\
\hline 28 & Xintai village, Suining & $30^{\circ} 55.773$ & $105^{\circ} 48.155$ & 289 & - & $\ldots$ \\
\hline 29 & Gongqiao village, Deyang 1\# & $31^{\circ} 14.423$ & $104^{\circ} 39.176$ & 484 & - & $\ldots$ \\
\hline 30 & Gongqiao village, Deyang 2\# & $31^{\circ} 14.573$ & $104^{\circ} 39.412$ & 450 & - & $\ldots$ \\
\hline 31 & Longfeng village, Deyang & $31^{\circ} 09.279$ & $104^{\circ} 27.022$ & 554 & - & $\ldots$ \\
\hline 32 & Guangba village, Dazhou & $31^{\circ} 33.665$ & $107^{\circ} 53.189$ & 347 & - & $\ldots$ \\
\hline 33 & Pujia town, Dazhou & $31^{\circ} 37.489$ & $107^{\circ} 52.073$ & 383 & - & $\ldots$ \\
\hline 34 & Baiyan village, Bazhong & $31^{\circ} 90.57$ & $106^{\circ} 73.457$ & 712 & - & $\ldots$ \\
\hline 35 & Fenggu village, Bazhong & $31^{\circ} 87.683$ & $106^{\circ} 70.452$ & 601 & - & $\ldots$ \\
\hline
\end{tabular}

${ }^{a}$ Molecular-detected disease index $(\mathrm{MDX})=$ DNA $(\mu \mathrm{g})$ of B. graminis f. sp. tritici /DNA (mg) of wheat; - indicates that no B. graminis f. sp. tritici was detected. 
powdery mildew infection of volunteer wheat, which is an important primary source of wheat powdery mildew. In this study, the latent infection level of B. graminis f. sp. tritici in volunteer wheat leaves was first quantified by real-time PCR. For the volunteer wheat leaves collected from the province-wide survey, the average observed infection rate over 2 years was $13.2 \%$, whereas the latent

Table 3. Molecular-detected disease index (MDX) of volunteer wheat in Ya'an and Wenjiang based on real-time polymerase chain reaction amplification

\begin{tabular}{|c|c|}
\hline Location, sampling date & MDX $^{\mathbf{a}}$ \\
\hline \multicolumn{2}{|l|}{ Wenjiang (altitude $=536 \mathrm{~m}$ ) } \\
\hline 1 June 2012 & 0.3154 \\
\hline 8 June 2012 & 0.0698 \\
\hline 11 June 2012 & 0.1663 \\
\hline 14 June 2012 & 0.3315 \\
\hline 22 June 2012 & 0.9533 \\
\hline 30 June 2012 & 0.1651 \\
\hline 6 July 2012 & - \\
\hline 13 July 2012 & 0.1551 \\
\hline 22 July 2012 & - \\
\hline 26 July 2012 & 0.0047 \\
\hline 29 July 2012 & 0.0142 \\
\hline 5 August 2012 & - \\
\hline 11 August 2012 & 0.1385 \\
\hline 17 August 2012 & - \\
\hline 18 September 2012 & 0.0147 \\
\hline 2 October 2012 & 1.1286 \\
\hline 18 October 2012 & - \\
\hline 23 October 2012 & 0.2319 \\
\hline 1 November 2012 & 0.1344 \\
\hline \multicolumn{2}{|l|}{ Ya'an $($ altitude $=595 \mathrm{~m})$} \\
\hline 11 June 2012 & 0.0437 \\
\hline 26 June 2012 & 1.0383 \\
\hline 13 July 2012 & 0.9141 \\
\hline 27 July 2012 & 0.0207 \\
\hline 1 August 2012 & 0.0284 \\
\hline 2 August 2012 & - \\
\hline 11 August 2012 & 0.0206 \\
\hline 28 August 2012 & 0.0159 \\
\hline 7 September 2012 & - \\
\hline 14 September 2012 & 0.0014 \\
\hline 29 September 2012 & 0.0002 \\
\hline 20 October 2012 & 0.0024 \\
\hline 28 October 2012 & - \\
\hline 29 October 2012 & 0.0008 \\
\hline 9 November 2012 & 21.0174 \\
\hline
\end{tabular}

Table 4. Molecular-detected disease index (MDX) of autumn-sown wheat in Ya'an and Wenjiang based on real-time polymerase chain reaction amplification

\begin{tabular}{|c|c|c|}
\hline Location, sampling time & Plot & MDX $^{\mathbf{a}}$ \\
\hline \multicolumn{3}{|l|}{ Wenjiang (altitude $=536 \mathrm{~m}$ ) } \\
\hline 26 November 2012 & 1 & - \\
\hline 26 November 2012 & 2 & - \\
\hline 26 November 2012 & 3 & 0.0023 \\
\hline 26 November 2012 & 4 & - \\
\hline 26 November 2012 & 5 & 0.0035 \\
\hline \multicolumn{3}{|l|}{ Ya'an $($ altitude $=595 \mathrm{~m})$} \\
\hline 16 November 2012 & 1 & 0.0005 \\
\hline 16 November 2012 & 2 & 0.0009 \\
\hline 16 November 2012 & 3 & - \\
\hline 16 November 2012 & 4 & - \\
\hline 16 November 2012 & 5 & - \\
\hline
\end{tabular}

rate was $39.5 \%$, which was much higher than the former rate. These results indicate that the infection conditions of $B$. graminis f. sp. tri$t i c i$ and the region of oversummering could be made more explicit by real-time PCR. Based on the evaluation of volunteer wheat leaves sampled through fixed-point observations, most of the leaves collected at different times were latently infected by $B$. graminis $\mathrm{f}$. sp. tritici according to real-time PCR detection. We also observed volunteer wheat in the same detected area in the summer. This study provides evidence at the molecular level that $B$. graminis f. sp. tritici can oversummer on continuous volunteer wheat via conidia and serve as an initial inoculum to infect autumn-sown wheat crop leaves. Thus, volunteer wheat plants must be eradicated, especially in areas of fungal oversummering, and wheat disease must be controlled in a timely manner to eradicate the disease center of wheat powdery mildew. The results of this study are consistent with previous studies in Guanzhong of Shanxi, Tianshui of Gansu, and Sichuan (Cao et al. 2011; Duan et al. 2002; Liu et al. 2012). Real-time PCR is much more sensitive than normal PCR and has been successfully applied to monitor the development of various pathogens in the host (Gachon and Saindrenan 2004; Qi and Yang 2002; Silvar et al. 2005; Zheng et al. 2013). Thus, real-time PCR can be a powerful tool for studying B. graminis f. sp. tritici.

From a disease control perspective, the MDX of wheat leaves and its relationship with the observed DX are key issues for disease forecasting and management. The real-time PCR assay can detect latent B. graminis f. sp. tritici infection at an early stage, which can provide guidance for successful disease control. However, MDX cannot reveal future infection situations of wheat in the field, due to the variation of future environmental conditions. Zheng et al. (2013) obtained linear relationships between the MDX and DX of wheat powdery mildew and found that the field distributions of MDX generally matched those of the observed DX in most fields. Clarifying the relationships of MDX, DX, and meteorological factors is the next objective. However, the real-time PCR assay is a powerful strategy for timely determination of the primary disease center. $B$. graminis f. sp. tritici can oversummer on continuous volunteer wheat via conidia and serve as the initial inoculum to infect the autumn-sown wheat leaves. Therefore, it is important to eliminate volunteer wheat in the fields, especially in places with relatively cooler temperatures and a humid climate.

\section{Acknowledgments}

We thank the staff at the plant protection station of all localities in Sichuan for their help in collecting samples of wheat powdery mildew.

\section{Literature Cited}

Bowen, K. L., Everts, K. L., and Leath, S. 1991. Reduction in yield of winter wheat in North Carolina due to powdery mildew and leaf rust. Phytopathology 81: 503-511.

Broscious, S. C., Frank, J. A., and Frederick, J. R. 1985. Influence of winter wheat management practices on the severity of powdery mildew and Septoria blotch in Pennsylvania. Phytopathology 75:538-542.

Cao, S. Q., Luo, H. S., Jin, S. L., Duan, X. Y., Zhou, Y. L., Jin, M. A., and Jia, Q. Z. 2011. Over-summering of Blumeria graminis f. sp. tritici in Tianshui of Gansu and effects of the sexual stage on infection cycle. Plant Prot. 37:115-119.

Costamilan, L. M. 2005. Variability of the wheat powdery mildew pathogen Blumeria graminis f. sp. tritici in the 2003 crop season. Fitopatol. Bras. 30:420-422.

Duan, S. K., Che, J. Y., Chen, Q. C., Feng, X. J., Wu, X. Y., and Wei, J. F. 2002. Analysis of summer wheat powdery mildew in the central Shaanxi plain. J. Xi'an Union Univ. 5:20-23.

Duan, S. K., Liu, C. H., Chen, X. F., Zhang, S. C., and Li, Q. J. 1995. The infection cycle of wheat powdery mildew in Guanzhong (Shanxi). Acta Agric. BorealiOccident. Sin. 4:35-39.

Gachon, C., and Saindrenan, P. 2004. Real-time PCR monitoring of fungal development in Arabidopsis thaliana infected by Alternaria brassicicola and Botrytis cinerea. Plant Physiol. Biochem. 42:367-371.

Gayoso, C., de Ilárduya, O., Pomar, F., and de Cáceres, F. 2007. Assessment of real-time PCR as a method for determining the presence of Verticillium dahilae in different solanaceae cultivars. Eur. J. Plant Pathol. 118:199-209.

Gorlenko, M. V. 1940. New results concerning the biology of Erysiphe graminis tritici March. Dokl. Akad. Nauk SSSR 27:866-870.

Huang, D., Yan, G., Gudmestad, N., and Skantar, A. 2017. Quantification of Paratrichodorus allius in DNA extracted from soil using Taqman probe and SYBR green real-time PCR assays. Nematology 19:987-1001. 
Jankovics, T., Komáromi, J., Fábián, A., Jäger, K., Vida, G., and Kiss, L. 2015. New insights into the life cycle of the wheat powdery mildew: Direct observation of ascosporic infection in Blumeria graminis f. sp. tritici. Phytopathology 105:797-804.

Justesen, A., Hansen, H., and Pinnschmidt, H. 2008. Quantification of Pyrenophora graminea in barley seed using real-time PCR. Eur. J. Plant Pathol. 122:253-263.

Koltin, Y., and Kenneth, R. 1970. The role of the sexual stage in the oversummering of Erysiphe graminis DC. f. sp. hordei Marchal under semiarid conditions. Ann. Appl. Biol. 65:263-268.

Lei, T. W., Feng, J. Y., and Duan, J. T. 1982. Preliminary study on the occurrence of wheat powdery mildew. Baiquan J. Agric. 2:19-25

Li, B., Cao, X. R., Chen, L., Zhou, Y. L., Duan, X. Y., Luo, Y., Bruce, D. L., Xu, X. M., Song, Y. L., Wang, B. T., and Cao, S. Q. 2013. Application of geographic information systems to identify the oversummering regions of Blumeria graminis f. sp. tritici in China. Plant Dis. 97:1168-1174.

Li, Y., Gu, Y. L., Wu, B. M., Jing, S. L., Cao, S. Q., Wang, X. M., Sun, Z. Y., Luo, Y., and Ma, Z. H. 2015. Establishment of a duplex TaqMan real-time PCR method for quantifying Puccinia striiformis f. sp. tritici and Blumeria graminis f. sp. tritici. Acta Phytopathol. Sin. 45:205-210.

Li, Y. H., Wang, J. M., Xu, F., Yang, G. Q., Song, Y. L., and Liu, L. L. 2016. Virulence structure of the wheat powdery mildew population in Henan Province in China during 2011-2014. Acta Phytopathol. Sin. 46:573-576.

Li, Y. S., Zheng, Y., Wei, C. L., and Liao, C. L. 1988. On the over-summering of wheat powdery mildew (Erysiphe graminis DC f. sp. tritici). Acta Phytopathol. Sin. 19:210.

Liu, N., Gong, G. S., Zhang, M., Zhou, Y., Chen, Z. X., Yang, J. Z., Chen, H. B., Wang, X. G., Lei, Y., and Liu, K. 2012. Over-summering of wheat powdery mildew in Sichuan Province, China. Crop Prot. 34:112-118.

Liu, X. K., Zhou, Y. L., and Liang, G. L. 1990. The research on oversummering of asexual generation of wheat powdery mildew in Nanyang. Plant Prot. 1:33.

Longrée, K. 1939. The effect of temperature and relative humidity on powdery mildew of roses. Cornell Univ. Agric. Exp. Stn. Mem. 223:1-41.

Miller, P. R., and Pollard, H. L. 1976. Multilingual Compendium of Plant Diseases, Vol. 1. American Phytopathology Society, St. Paul, MN, U.S.A.

Mzhavanadze, A. V. 1974. Life history of the causal agent of wheat powdery mildew in east Georgia. Fitopatology 8:117-119.

Nikitin, M. M., Statsyuk, N. V., Frantsuzov, P. A., Dzhavakhiya, V. G., and Golikov, A. G. 2018. Matrix approach to the simultaneous detection of multiple potato pathogens by real-time PCR. J. Appl. Microbiol. 124:797-809.

Padalino, O., Antonicelu, M., and Grasso, V. 1970. Biology of E. graminis f. sp. tritici in the environmental conditions of S. Italy. Phytopathol. Mediterr. 9:122-135.

Price, T. V. 1970. Epidemiology and control of powdery mildew (Sphaerotheca pannosa) on roses. Ann. Appl. Biol. 65:231-248.

Qi, M., and Yang, Y. N. 2002. Quantification of Magnaporthe grisea during infection of rice plants using real-time polymerase chain reaction and Northern blot/phosphoimaging analyses. Phytopathology 92:870-876.
Schena, L., Nigro, F., Ippolito, A., and Gallitelli, D. 2004. Real-time quantitative PCR: A new technology to detect and study phytopathogenic and antagonistic fungi. Eur. J. Plant Pathol. 110:893-908.

Silvar, C., Díaz, J., and Merino, F. 2005. Real-time polymerase chain reaction quantification of Phytophthora capsici in different pepper genotypes. Phytopathology 95:1423-1429.

Tang, X. L., Cao, X. R., Xu, X. M., Jiang, Y. Y., Luo, Y., Ma, Z. H., Fan, J. R., and Zhou, Y. L. 2017. Effects of climate change on epidemics of powdery mildew in winter wheat in China. Plant Dis. 101:1753-1760.

Tao, J. F., Shen, Y. Z., Qing, J. Z., Liu, Z. S., and Jiang, C. P. 1976. The biology of Erysiphe graminis DC. f. sp. tritici E. M. Marchal in relation to the incidence of wheat powdery mildew in west Sichuan, China. Acta Microbiol. Sin. 16:318-327.

Ts'ao, S. H. 1960. Powdery mildew of wheat and its control in conditions of the Leningrad region. Mem. Inst. Agron. Leningr. 80:133-139.

Tu, J. H., Li, Y., Liao, H. M., Xu, X. Q., and Cheng, B. 1999. The occurrence of Erysiphe graminis DC. f. sp. tritici E. M. Marchal in Sichuan Province. Southwest Chin. J. Agric. Sci. 12:61-64.

Turner, D. M. 1956. Studies on cereal mildew in Britain. Trans. Br. Mycol. Soc. 39:495-506.

Tursumbaev, A. 1974. Some biological characteristics of the causal agent of wheat powdery mildew. Vestn. Skh. Nauki Kaz. 7:46-48.

Wang, Z. Z., Li, H. W., Zhang, D. Y., Guo, L., Chen, J. J., Chen, Y. X., Wu, Q. H., Xie, J. Z., Zhang, Y., Sun, Q. X., Dvorak, J., Luo, M. C., and Liu, Z. Y. 2015. Genetic and physical mapping of powdery mildew resistance gene MlHLT in Chinese wheat landrace Hulutou. Theor. Appl. Genet. 128:365-373.

Winton, L. M., Manter, D. K., Stone, J. K., and Hansen, E. M. 2003. Comparison of biochemical, molecular, and visual methods to quantify Phaeocryptopus gaeumannii in Douglas-Fir foliage. Phytopathology 93:121-126.

Wyand, R. A., and Brown, J. K. M. 2003. Genetic and forma specialis diversity in Blumeria graminis of cereals and its implications for host-pathogen co-evolution. Mol. Plant Pathol. 4:187-198.

Yang, D. B., and Liu, X. K. 1994. Over-summering of cleistothecia of Erysiphe graminis f. sp. tritici in Beijing district. Acta Phytopathol. Sin. 4:336-392.

Zeng, X. W., Luo, Y., Zheng, Y. M., Duan, X. Y., and Zhou, Y. L. 2010. Detection of latent infection of wheat leaves caused by Blumeria graminis f. sp. tritici using nested PCR. J. Phytopathol. 158:227-235.

Zhang, Z. D., and Li, Z. Q. 1993. The laws of occurrence of powdery mildew of wheat in central area of Shaanxi Province. Acta Univ. Agric. BorealiOccident. Sin. 21:25-31.

Zhao, J. L., Xu, C., Xu, J. P., Huang, L. S., and Zhang, D. Y. 2018. Forecasting the wheat powdery mildew (Blumeria graminis f. sp. tritici) using a remote sensing-based decision-tree classification at a provincial scale. Australas. Plant Pathol. 47: 53-61.

Zheng, Y. M., Luo, Y., Zhou, Y. L., Zeng, X. W., Duan, X. Y., Cao, X. R., Song, Y. L., and Wang, B. T. 2013. Real-time PCR quantification of latent infection of wheat powdery mildew in the field. Eur. J. Plant Pathol. 136:565-575. 